\title{
Incidence of Breast Muscles Abnormalities in Chicken Broiler
}

\author{
${ }^{\mathbf{1}}$ Abdelrahman H. A; ${ }^{\mathbf{2}}$ Eman H. Hamza and ${ }^{\mathbf{3}}$ Nashwa M. Ismail \\ ${ }^{1}$ Department of Food Hygiene, Faculty of Veterinary Medicine, Suez \\ Canal University, ${ }^{2}$ Veterinarian, ${ }^{3}$ Animal Research Institute3, \\ Ismailia Egypt
}

\begin{abstract}
:
During the last 60 years the size of the breast muscle was increased through the improvements in the growth rate and yield of the chicken broilers. By introducing different genetic selection and application with improvement of chicken nutrition and management led finally to serious breast meat abnormalities that influenced their quality and left a negative impact on broiler meat sector. The most prevalent abnormalities include Deep Pectoral Muscle myopathy (DPM) green muscle disease or Oregon disease, White Striping (WS), and Woody Breast (WB). Every year an extensive research all over the world on the real causes of breast muscles condemnation was conducted in order to reduce both breast muscles abnormalities and financial losses. Therefore this study was conducted by inspection of 3.720 .000 chicken broiler carcasses at North Delta abattoir, Egypt during chicken processing the incidence of Green Muscle (with their three stages), white Strips and Wooden Breast were 20280 $(0.5 \%), 1248(0.03 \%)$ and $1872(0.05 \%)$ respectively. The total economic loss during 2019 for green muscle abnormality according to the Egyptian salary was 124800 L.E., for WS and WB were 31200 and 48800 L.E respectively.
\end{abstract}

Keywords: Green muscle (DPM), white striping (WS), woody breast (WB).

\section{Introduction:}

Poultry production is considered one of the most important sections of agriculture throughout the world, whatever the differences in the production methods from that of the raring as free-range in some countries to the highly advanced intensive breeding systems which are used in other regions of the world (Yang and Jiang, 2005). Extensive research was carried out to declared the causes of poultry carcasses condemnation was conducted in order to reduce 
both chicken carcasses abnormalities and financial losses (Ansong-Danquah, 1987; Santana et al., 2008; Dzoma et al., 2009; Ferreira et al., 2012). The Pectoralis muscles ( $\mathrm{P}$. major and P. minor) of breast muscles are of considerable value to the chicken broiler industry, and the P. major specially is being the most predominant meat producer and consequently that of the greatest economic value (USDA, 2016). The sensational enhancements in the growth rate, size and yield of the breast muscle in poultry breeding introduced several serious chicken muscle abnormalities that affect the quality of breast meat, these abnormalities include DPM myopathy defined as green muscle disease, WS, and WB that have genuine negative ramifications to the breast muscles which altered their structural, functional and metabolic characteristics

(Petracci et al., 2015; Velleman and Clark, 2015). The DPM abnormality is identified as ischaemic necrosis of the $P$. minor muscle in chicken broiler (Richardson et al., 1980; Wight and Siller, 1980; Bianchi et al., 2006) selected for increased breast muscle growth (Siller, 1985). The DMP is a hidden problem in large broiler chickens and it could be detected only during deboning and portioning of the breast muscle processing
Lien et al. (2012). The breast fillets with the $\mathbf{W B}$ condition is characterized by abnormal hardness and rigidity of the muscle surface with a distinct ridge on the anterior of the $\mathrm{P}$. major (Sihvo et al., 2014). While WS is a condition which characterized by white striations on the breast muscle of chicken broilers and during the histopathological examination of the WS and WB showed myodegeneration and necrosis, fibrosis and lipidos is (Kuttappan et al. (2016). The WB abnormality is appearing to be the most prevalent in breast muscles and characteristics by the asymmetrical shape of the P. major obtained especially from large chicken broilers. Normally the breast muscles fillets of large chicken broilers are usually sectioned to provide the foodservice markets with chicken fillies of symmetrical form. The characteristics lesions associated with WB are typically present on the ventral surface of the P. major muscle (Sihvo et al., 2014; Clark and Velleman, 2016).

\section{Mate rials and methods:}

The study was conducted at Damietta poultry abattoir, Damietta governorate. This abattoir is considered as one of the largest and very new province abattoir in Egypt which built in 2016.

\section{Aim of study}


The investigations were conducted on broiler chicken at an age of 35-40 day with average live body weight of about $2.5 \mathrm{Kg}$ and nearly $1.800 \mathrm{Kg}$ carcass yield during the year 2019 for evaluation of slaughtered carcasses abnormalities with special references to; Green muscle, wooden breast and White striping abnormalities.

2 Poultry Slaughtering and Inspection was carried out according to Egyptian Official Facet Gazette (EOFG) No 257 (1986):

\subsection{Antemortem ins pection}

\subsubsection{At Abattoir}

Antemortem inspection was carried out for poultry waiting slaughtering at abattoir during unloading and hanging on the shackles according to the procedure recommended by EOFG No 257 (1986). The inspection was done by the veterinarian which responsible for poultry meat inspection. The inspector was looking for any abnormalities which may be seen during hanging the unloaded live birds on the shackles.

2.1.1.1 Slaughtering and blee ding.

2.1.1.2 Scalding and Defeathering.

2.1.1.3 Whole carcasses inspection.

2.1.1.4 Partially eviscerated carcasses inspection.

2.1.1.5 Chilling, weighting and grading.
The carcasses after initial chilling were graded according to the degree of abnormalities into: Grade A in which carcasses are free from any abnormalities and packed as whole poultry carcass. Grade B in which the carcasses showed some minor carcasses abnormalities due to transport handling or due to processing faults were further processed into poultry meat cuts which includes thighs, breasts and wings.

\subsection{Pos tmortem Examination}

2.2.1 Green Muscle Disease. Aviagen (2019)

The deep pectoral myopathy disorder was detected during whole poultry carcass inspection ,the carcass showed tight fascia of the underlying breast muscle , swollen, pale and edematous with necrosis in the middle 30 $60 \%$ of the muscle, which is only evident after processing or necropsy as streaks of white to greenish band and may be unilateral or bilateral lesions which followed by more chronic lesions lead to finally in flattening of the breast muscle which can be palpated in postmortem examination. The green muscle appears when edema disappears and the necrotic muscle becomes prominent and drier in the whole deep pectoral. Also necrotic muscle was shrinks and enclosed in a fibrous capsule and the 
sternum becomes roughened and irregular.

\subsubsection{White Striping B reast} Muscle. Petracci et al. (2013)

WS abnormality showed white striations on the surface which parallel to the direction of the breast muscle fibers. The WS abnormality can be categorized based on the visual evaluation of their intensity and the breast muscle fillets with higher degrees of WS were heavier and thicker.

\subsubsection{Wooden Breast Muscle.} Xing et al. (2020)

WB at postmortem examination was bulged, hard and rigid muscles with hemorrhage on the surface combined with a light yellow viscous exudates. WB becomes tough in consistency on palpation. In severe cases of WB appears as prominent ridge like bulge on posterior area of the fillet may be noticed and in some cases, a clear viscous fluid, petechial multifocal lesions on the fillet muscle surface was observed.

\section{His topathological}

examination.

Histological examination was carried out according to Banchroft et al. (1996).

A duplicate 1x1 cm blocks from all the poultry meat samples were fixed in 10\% formalin saline for 24 hours. The fixed samples were washed then followed by dehydration using methyl, ethyl and absolute ethyl, then cleared in xylene and embedded in paraffin at $56^{\circ} \mathrm{C}$ in hot air oven for 24 hours. Paraffin bees wax tissue blocks were prepared and sectionend. The obtained tissue sections were collected, deparaffinized and stained by hematoxylin and eosin stains ready to be examined under microscope. The breast muscle fibers are swollen and eosinophilic with discoid necrosis. Absent or faint of the nuclei and an inflammatory reaction was surrounding the necrotic tissue. Vascular lesions, intimae proliferation, and aneurysm formation may be seen.

\section{Results and discussion:}

Many breast muscles abnormalities can affect the chicken carcass in their appearance, technological quality and cause great economic losses due to the condemnation of carcasses or viscera. The results given in Table (1) and Fig. (1) revealed that the total number of slaughtered poultry during the year 2019 in the slaughter plant at Damietta province, Egypt was 3.720.000 chicken broiler and after postmortem inspection and during carcasses processing, the incidence of Green Muscle, white Strips and Wooden Breast were $20280(0.5 \%), 1248(0.03 \%)$ and $1872(0.05 \%)$ respectively. The results obtained in this 
studies for Green muscle disease were lower than that recorded by Bianchi et al. (2006) and higher than that recorded by Alamoti et al. (2016). While for white striping the results were lower than that recorded by Ferreira et al., (2014), Kuttappan et al. (2012) and Lorenzi et al. (2014). While for wooden breast the results were lower than that recorded by Owens (2014) and Gratta et al. (2017). Also the results given in Table (2) revealed that the number and percentage of infected chicken broiler with green muscle disease four stages according to the classification mentioned by Bilgili and Hess (2008) was 20280(0.5\%) which could be detected in dressed chicken broiler carcasses during breast muscle processing for stage one $2028(10 \%)$, for stage two $6084(30 \%)$ and for stage three was $12168(60 \%)$. The variation in the results obtained was attributed to the degree of management system, breeding, type of feeding, degree of the growth rate, catching technique of broiler chicken at the poultry farm as stress and noise during harvesting which lead to wing flapping that increase occurrence of Breast muscle disease. The result given in Table (3) showed the weights of condemned GM abnormality stages 1,2 and 3 were $156 \mathrm{~kg}(10 \%), 468 \mathrm{~kg}$ $(30 \%)$ and $936 \mathrm{~kg}(60 \%)$ respectively with total economic loss according to the Egyptian salary by 124800 L.E. The result given in Table (4) showed the weights and economic loss of condemned WS and $\mathrm{WB}$ in $\mathrm{Kg}$ were $624 \mathrm{~kg}$ and $936 \mathrm{~kg}$ equal to 31200 and 48800 L.E respectively. The economic loss was calculated as 50 L.E/ $\mathrm{kg}$ because the above two abnormalities were minced and sold in low price as poultry breast minced meat (30 L.E loss $/ \mathrm{kg}$ ). The results recorded were lower that recorded by Kuttappan et al. (2016) during a studies that carried out and recorded a economic losses due to WS ranged from $\$ 200$ million to $\$ 1$ billion per year in U.S.

The histopathological examination as given in Image (1) showed the normal breast fillet and normal tissue architecture with cellular details of muscle bundles. While in Image (2) revealed that the upper section from wooden fillet showed massive collagen fibers were proliferated between the muscles bundles that showed hyaline degeneration and or Zenker's necrosis with few inflammatory cells infiltration. In Image(3) the middle section of wooden fillet showed marked edema and massive collagen fiber proliferation and mononuclear cell infiltration that replaced the necrotic and degenerated muscle bundles and 
in Image(4) from the down section of wooden fillet showed edema, hyaline degeneration and Zenker's necrosis of the muscle bundles without inflammatory reactions, in Image(5) section from the white striping fillet showed more diffuse reactions and the muscle bundles were more separated and shrunken. The histopathological examination of the first stage of green muscle disease Image (6) showed diffuse edema and massive mononuclear cell infiltrations were evident between the muscle bundles.
While in the second stage Image (7) of GM showed massive mononuclear inflammatory cells infiltrations. In the third stage Image (8) of GM showed patches of Zenker's necrosis in the muscle bundles with few mononuclear inflammatory cells. The histopathologic al examination results given in Image (9) showed normal deep muscle with little edema and focal hyaline degeneration. Images 10, 11, and 12 showed green muscle disease in chicken boiler, while 13 and 14 showed white stripping conditions.

Table (1): Incidence of Green Muscle (GM), White Strips (WS) and Wooden Breast (WB) abnormalities in examined chicken broiler carcasses

\begin{tabular}{|c|c|c|c|c|c|c|}
\hline $\begin{array}{c}\text { No. of } \\
\text { Slaughtered } \\
\text { chicken broiler }\end{array}$ & \multicolumn{2}{|c|}{$\begin{array}{c}\text { Green } \\
\text { Muscle }\end{array}$} & \multicolumn{2}{c|}{$\begin{array}{c}\text { White } \\
\text { strips }\end{array}$} & \multicolumn{2}{c|}{$\begin{array}{c}\text { Wooden } \\
\text { B re ast }\end{array}$} \\
\hline \multirow{2}{*}{3.720 .000} & $\mathrm{~N} 0$ & $\%$ & $\mathrm{~N} 0$ & $\%$ & $\mathrm{~N} 0$ & $\%$ \\
\cline { 2 - 7 } & 20280 & 0.5 & 1248 & 0.03 & 1872 & 0.05 \\
\hline
\end{tabular}

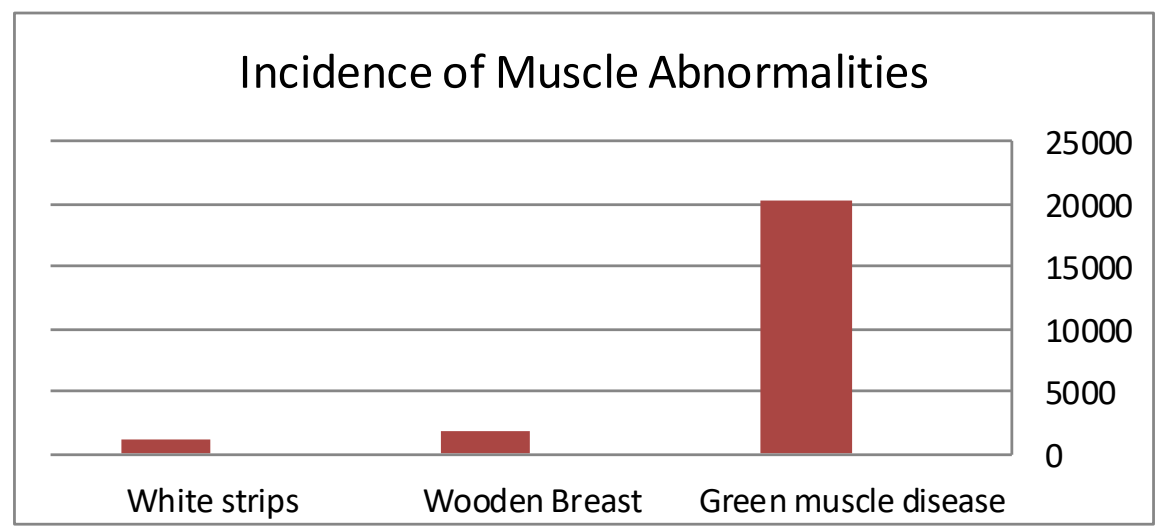

Fig (1): Incidence of muscle abnormalities 
Table (2): Incidence of the Green Muscle disease stages in dressed chicken broiler caracaras.

\begin{tabular}{|c|c|c|c|c|c|c|}
\hline $\begin{array}{c}\text { No. of infected } \\
\text { chicken }\end{array}$ & \multicolumn{2}{|c|}{ Stage 1 } & \multicolumn{2}{c|}{ Stage 2 } & \multicolumn{2}{c|}{ Stage 3 } \\
\hline \multirow{2}{*}{20280} & N0 & $\%$ & No & $\%$ & No & $\%$ \\
\cline { 2 - 7 } & 2028 & 10 & 6084 & 30 & 12168 & 60 \\
\hline
\end{tabular}

Stage 1: Characterized by acute inflammatory lesion in which the deep pectoral muscle is very red and hemorrhagic

Stage 2: Fish flesh like and the fillet well defend and surrounded by a hemorrhagic ring, and become pale in colour with coagulative necrosis.

Stage 3: Progressive degeneration and greening of the damaged tissues was noticed. Only the middle part of the fillet is involved and the progressive green part is in parallel with the loss of cellular structure, appeared lie as paste like consistency.

Table (3): Weights of condemned GM abnormality and their economic Loss

\begin{tabular}{|c|c|c|c|c|}
\hline Stage 1 & Stage 2 & Stage 3 & $\begin{array}{c}\text { Total Weights of } \\
\text { condemned GM } \\
\text { cases }\end{array}$ & $\begin{array}{c}\text { Economic } \\
\text { loss/L.E }\end{array}$ \\
\hline $156 \mathrm{~kg}$ & $468 \mathrm{~kg}$ & $936 \mathrm{~kg}$ & $1560 \mathrm{~kg}$ & 124800 \\
\hline
\end{tabular}

Local Price of the breast muscle (80 L.E)

Table (4): Economic loss caused by Examined Abnormalities

\begin{tabular}{|c|c|c|c|}
\hline Abnormalities & Weight/kg & $\begin{array}{l}\text { Average } \\
\text { Price/Kg }\end{array}$ & $\begin{array}{c}\text { Economic } \\
\text { loss/L.E }\end{array}$ \\
\hline WS & 624 & 50 & 31200 \\
\hline WB & 936 & 50 & 48800 \\
\hline
\end{tabular}




\section{His topathology Images}

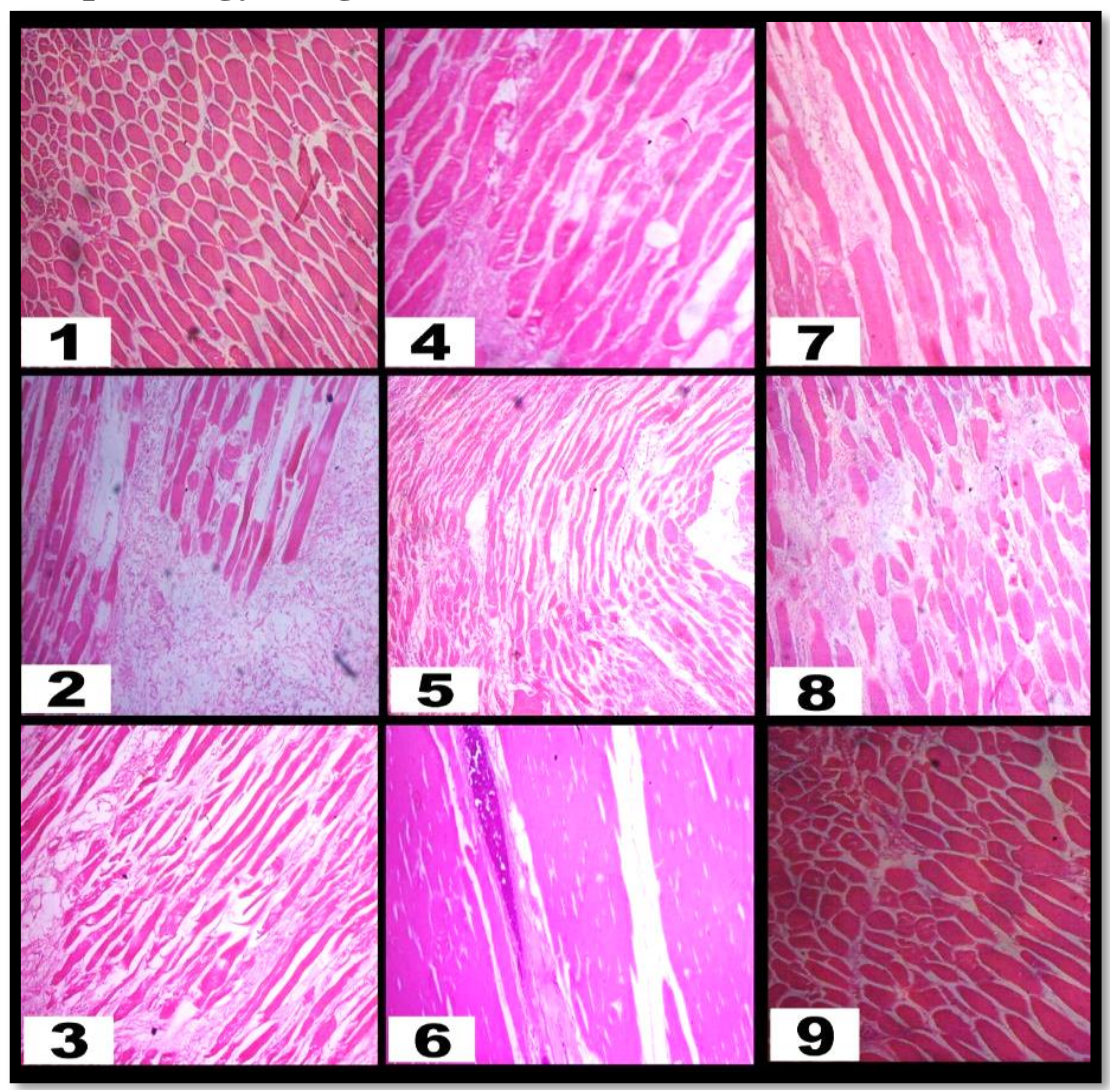

Image (1): Normal fillet stained with H\&E stain, X 250 showing normal tissue architecture and cellular details of muscle bundles.

Image (2): Upper section from wooden fillet stained with H\&E stain, X 250 showing massive collagen fibers were proliferated between the muscles bundles that exhibited by hyaline degeneration and or Zenker's necrosis with few inflammatory cells infiltration.

Image (3): Middle section from wooden fillet stained with H\&E stain, X 250 showing marked edema and massive collagen fiber proliferation and mononuclear cell infiltration that replaced the necrotic and degenerated muscle bundles.

Image (4): Down section from w ooden fillet stained with H\&E stain, X 250 showing edema, hyaline degeneration and Zenker's necrosis of the muscle bundles without inflammatory reactions.

Image (5): White striping fillet stained with H\&E stain, X 250 showing more diffuse reactions which made muscle bundles more separated shrunken. 
Image (6): Green muscle stage 1 stained with H\&E stain, X 250 showing diffuse edema and massive mononuclear cell infiltrations were evident between the muscle bundles.

Image (7): Green muscle stag 2 stained with H\&E stain, X 250 showing massive mononuclear inflammatory cells infiltrations.

Image (8): Green muscle stage 3 stained with H\&E stain, X 250 showing patches of Zenker's necrosis in the muscle bundles with few mononuclear inflammatory cells.

Image (9): Normal deep Green muscle stained with H\&E stain, X 250 as normal fillet but with little edema and focal hyaline degeneration were evident.

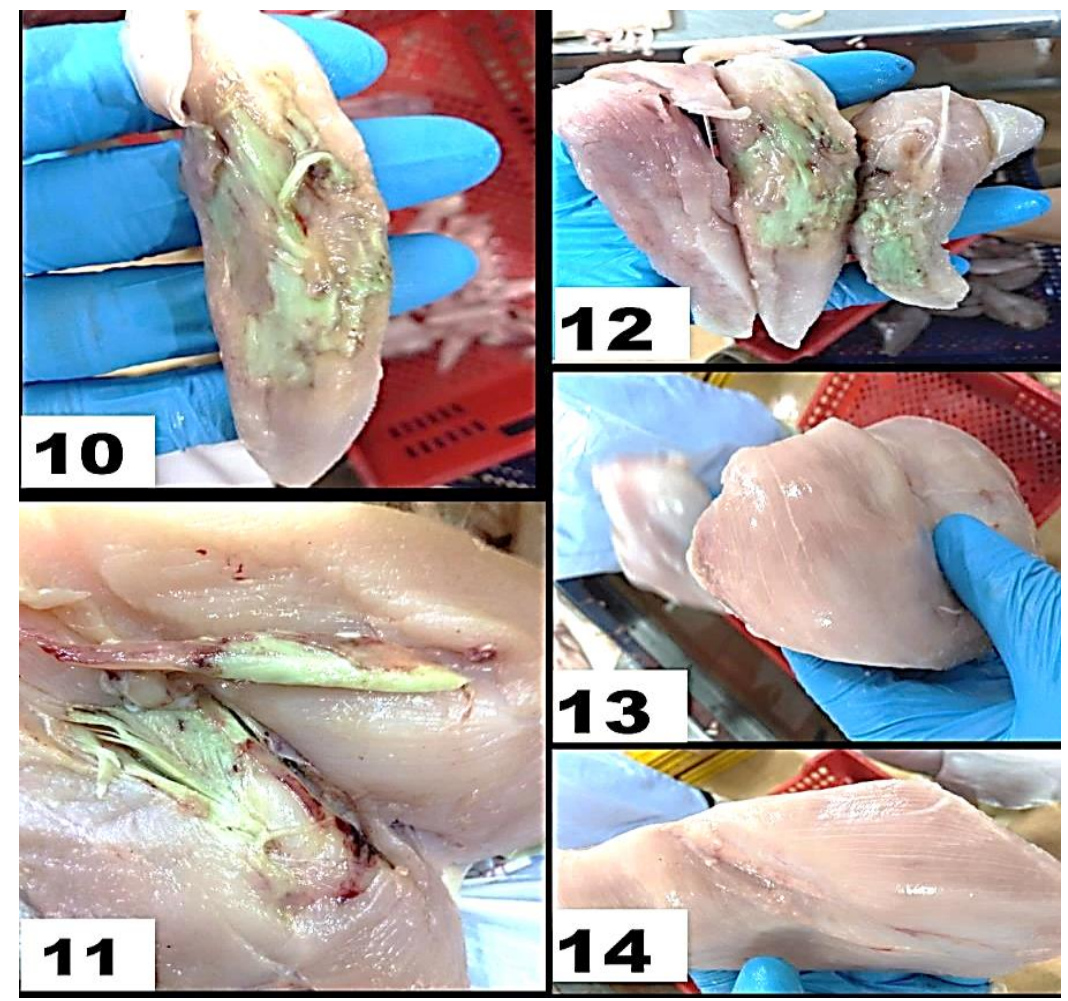

Image (10): $3^{\text {rd }}$ stage of Green muscle disease

Image (11): Green muscle Disease

Image ) 12): Different stages of Green muscle disease.

Image (13) \& (14): White striping muscle.

\section{Conclusion:}

From this study it could be concluded that the breast muscle abnormalities is a global problem and varies from country to other in their amount and severity cause yearly great economic losses. The improvements in the growth rate and yield of the chicken broilers especially during the first 10 days breeding is important for 
the muscle development in addition the avoidance of sudden growth with minimizing flock disturbance to prevent wing flapping to reduce the occurrence of these abnormalities. The severity of the occurrence of myopathies in the breast muscles has a negative impact not only on the consumer acceptance but also on the economic impact in poultry industry.

\section{Conflict of interest statement:}

The authors did not have any conflict of interest

\section{References}

Alamoti MP, Khale dian S, and Mohammadi M (2016): Study of green muscle disease in some condemned broiler chicken from Iran.

https://link.springer.com/journal 1580. 25:1193-1196.

Aviagen (2019): Breast Muscles Myopathies. A review of Aviagen meat quality work group. https://en.aviagen.com.

Ansong-Danquah J (1987): A survey of carcass condemnation at a poultry abattoir and its application to disease management. Can Vet J 28:5356.

Bancroft, $J$ and Stevens, A (1996): Theory and practice of histological techniques. $4^{\text {th }}$ Edition Churchill Livingstone, Edinburgh. No. of Pages: 766

Bianchi M., Petracci M., Franchini A., and Cavani C.
(2006): The occurrence of deep pectoral myopathy in roaster chickens. Poultry Science 85:1843-1846.

Bilgili S.F and Joseph $H$. (2008): Reducing the incidence of green muscle disease in broiler flocks. www.aviagen.com.

Clark DL. and Velleman SG. (2016): Spatial influence on breast muscle morphological structure, myofiber size, and gene expression associated with the wooden breast myopathy in broilers. Poultry Science Volume 95 Issue 12:2930-2945.

Dzoma BM, Pansiri E, Segwagwe BE (2009): A retrospective study on the prevalence of ostrich carcass and organ condemnations in Botswana. Trop Anim Health Prod 41:443-448.

Egyptian Official Facet Gazette No 517 (1986): Meat and meat products, poultry inspection. Vol 257:1-77

Fe rreira T.Z, Casagrande R.A, Vieira S.L, Driemerier D, and Kindlein L. (2014): An investigation of a reported case of white striping in broilers. Journal of Applied Poultry Research 23:748753.

Ferreira TZ, Sesterhenn R, Kindlein L (2012): Economic losses of main causes of condemnation of the broiler carcass in a slaughterhouse under federal inspection on Rio 
Grande do Sul, Brazil. Acta Sci Vet 40:1021.14.

Gratta F, Birolo M, Piccirillo A, Petracci M, Maertens L, Xiccato G, Trocino A. (2017): Effects of the feeding system on performance and myopathy occurrence in two broiler chicken genotypes. Ital J Anim Sci 16:48.

Kuttappan V.A, Goodgame S.D, Bradley C.D, Mauromoustakos A, Hargis B.M, Waldroup P, Owens C.M. (2012): Effect of different levels of dietary vitamin E (DL$\alpha$-tocopherol acetate) on the occurrence of various degrees of white striping on broiler breast fillets. Poult Sci 91:3230-3235.

Kuttappan V.A, Hargis B.M, Owens C.M. (2016): White striping and woody breast myopathies in the modern poultry industry: A review. Poultry Sci 95:2724-2733.

Lien R.J, Bilgili S.F, Hess J.B, Joiner K.S. (2012): Induction of deep pectoral myopathy in broiler chickens via encouraged wing flapping. Journal of Applied Poultry Research 21(3):556-562

Lorenzi M, Mudalal S, Claudio C, Petracci M.( 2014): Incidence of white striping under commercial conditions in medium and heavy broiler chickens in Italy. Journal of Applied Poultry Research 23:754-758.
Owens CM. (2014): Identifying quality defects in poultry processing. Watt Poultry USA, pp 42-50.

Petracci M; Mudale, S; Bonfiglio, A and Cavani C. (2013): Occurrence of white striping under commercial conditions and its impact on breast meat quality in broiler chickens. Poultry Science 92:1670-1675http://dx.doi.org/ 10.3382/ps. 2012-0300.

Petracci M, Mudalal S, Soglia F, Cavani C. (2015): Meat quality in fast-growing broiler chickens. World' s Poult Science 71:363-374.

Richardson, J.A., Burge ner, J., Winterfield, R.W. \& Dhillon, A.S. (1980): Deep pectoral myopathy in seven-week old broiler chickens. Avian Diseases, 24, 1054-1059.

Santana AP, Murata LS, de Freitas CG, Delphino MK, Pimente CM (2008): Causes of condemnation of carcasses from poultry in slaughterhouses located in State of Goiás, Brazil. Cienc Rural 38:2587-2592.

Sihvo, H.-K., K. Immonen, and E. Puolanne. (2014): Myodegeneration with fibrosis and regeneration in the pectoralis major muscle of broilers. Vet Pathol 51:619-623.

Siller W.G. (1985): Deep pectoral myopathy: A penalty of successful selection for muscle growth. Poultry Science 64:1591-1595. 
USDA. (2016). Broiler Market News Report. Des Moines, IA: Livestock Poultry Grain Market News Service, 49.

Velleman S.G, Clark D.L (2015): Histopathologic and myogenic gene expression changes associated with wooden breast in broiler breast muscles. Avian Dis. 59:410-418.

Wight P.A.L, Siller W.G (1980): Pathology of Deep Pectoral Myopathy of Broilers.
Veterinary Pathology Journal. vol. 17, Issue 1: 29-39.

Xing, T. Zhao. X. Zhang, L. Li. J. Zhou, G. H. , Xu ,X. and Gao, F. (2020): Characteristics and incidence of broiler chicken wooden breast meat under commercial conditions in China. Poultry Science Volume 99, Issue 1, , Pages 620-628

Yang N, Jiang RS. (2005): Recent advances in breeding for quality chickens. World's Poult Sci J.; 61:373-382.

لر اسات على بعض التغيرات غير الطبيعية في ذبائح الاجاج اللاحم في مسلخ للاو اجن

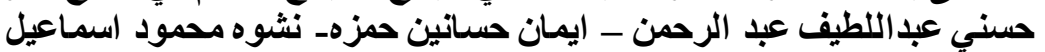

$$
\text { الملخص العربي }
$$

في خلال السنو ات الستين الماضية ، تم زيادة حجم عضلة صلئل العدر الدجاج اللاحم بشكل كبير

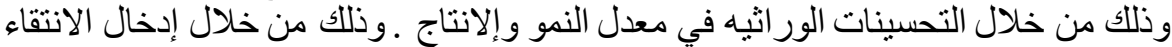

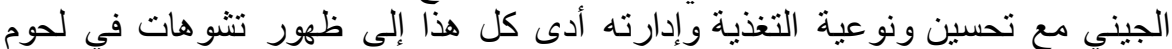

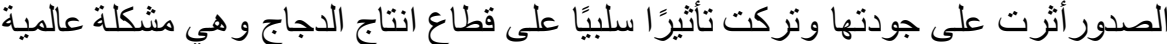

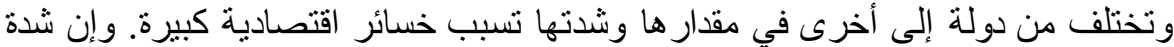

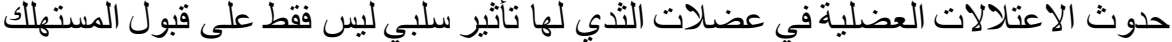

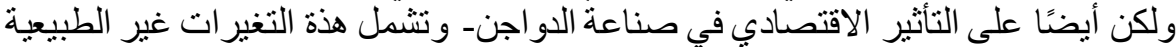

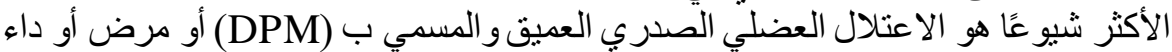

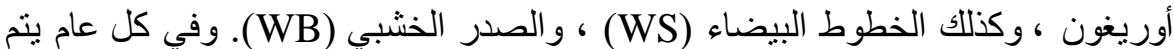

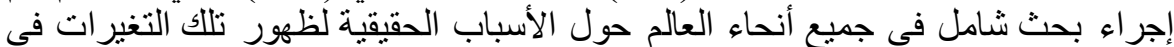

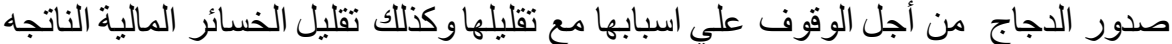

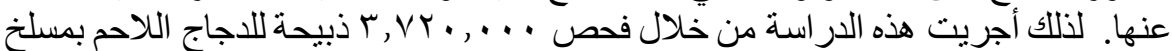

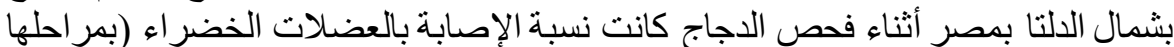

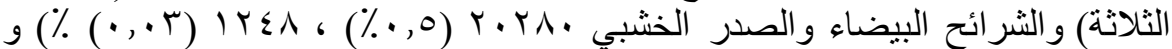

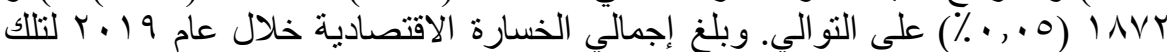

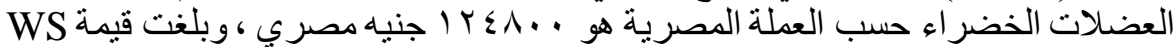

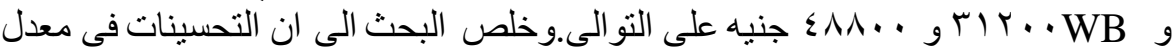

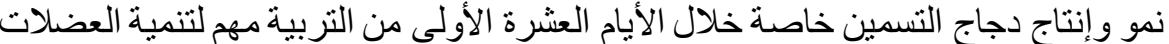

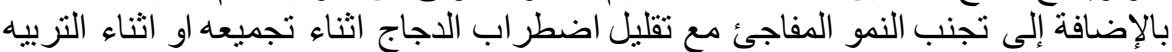
لكنع رفرفة الجناح بشكل مفاجئ لتقليل حدوث هذه الغير ات العضئ العضلية الصدريه 